\title{
Prevalence and Identification of Digestive Tract Protozoa in Goats in Labang District Bangkalan Regency
}

\section{Prevalensi dan Identifikasi Protozoa Saluran Pencernaan pada Kambing di Kecamatan Labang Kabupaten Bangkalan}

\author{
${ }^{1)}$ Warda Nafalizza Efendi, ${ }^{2)}$ Lucia Tri Suwanti, ${ }^{3)}$ Abdul Samik, ${ }^{2)}$ Poedji Hastutiek, ${ }^{2)}$ Mufasirin, \\ ${ }^{2)}$ Kusnoto \\ ${ }^{1)}$ Student, Faculty of Veterinary Medicine, Universitas Airlangga \\ ${ }^{2)}$ Department of Veterinary Parasitology, Faculty of Veterinary Medicine, Universitas Airlangga \\ ${ }^{3)}$ Deprtement of Veterinary Reproduction, Faculty of Veterinary Medicine, Universitas Airlangga \\ Received: 07-08-2019, Accepted: 14-08-2019, Published Online: 16-o8-2019
}

\begin{abstract}
This study aims to determine the prevalence and to identify gastrointestinal protozoa in goats in Sub-district of Labang, Bangkalan Regency, Madura, Indonesia. The research was conducted in April - July 2019 with 100 samples of goat's stool. Examination was done in the laboratory of Parasitology in Faculty of Veterinary Medicine, Airlangga University using direct smear, sedimentation and flotation methods. The result showed that goats in Labang, Bangkalan Regency were infected by protozoa Eimeria sp. and Blastocystis sp. and the prevalence was $84 \%$. There were no significant differences in the age and sex of goats $(\mathrm{p}>0.05)$.
\end{abstract}

Key words : Prevalence, Gastrointestinal Protozoa, Goat, Bangkalan, Madura.

\section{Pendahuluan}

Labang merupakan salah satu kecamatan di Kabupaten Bangkalan yang mayoritas penduduk memelihara ternak kambing. Populasi kambing di kecamatan Labang pada tahun 2018 sebesar 6.735 ekor (Dinas Peternakan Jawa Timur, 2018). Masalah yang sering ditemui di lapangan terkait ternak kambing yaitu sebagian besar kondisi ternak kambing di Kecamatan Labang tampak kurus. Hal ini berkaitan dengan penelitian yang dilakukan oleh Thlama dkk. (2016) bahwa infeksi protozoa secara signifikan mempengaruhi skor kondisi tubuh pada kambing. Selain kondisi fisik yang terlihat, umur mempengaruhi tingkat infeksi pada kambing. Menurut Jittapalapong dkk. (2012), kambing muda lebih rentan terinfeksi oleh protozoa saluran pencernaan. Pernyataan Alexander dan Stimson (1988) mengenai jenis kelamin juga mempengaruhi tingkat infeksi. Kambing betina memiliki respon terhadap infeksi lebih tinggi dikarenakan pengaruh dari hormon estrogen dan androgen yang terlibat dalam immunoregulasi.

Menurut Yulianto (2007), penyebaran protozoa terjadi cukup tinggi. Penyebabnya adalah kondisi geografis di Indonesia yang beriklim tropis dan didukung oleh udara yang lembab dan panas. Secara geografis lokasi Kecamatan Labang Kabupaten Bangkalan terletak di daerah dekat pantai dengan kondisi suhu dan kelembaban yang tinggi sehingga memungkinkan untuk penularan infeksi protozoa pada kambing.

Parasit protozoa menyebabkan kerusakan pada epitel usus sehingga menurunkan kemampuan usus dalam mencerna dan menyerap zat makanan serta menurunkan produksi enzim yang berperanan dalam proses pencernaan sehingga menurunkan produktivitas ternak (Zalizar, 2017). Hal ini dapat berdampak kerugian ekonomi yang besar bagi para peternak. Gejala klinis yang disebabkan oleh infeksi protozoa diantaranya diare, penurunan berat badan, dehidrasi, dan kelelahan (Daugschies dan Najdrowski, 2005).

Protozoa pada saluran pencernaan yang menginfeksi kambing Cryptosporodium sp., Giardia intestinalis, Balantidium coli, Eimeria sp., dan Entamoeba sp. (Levine, 1995). Blastocystis sp. juga ditemukan dalam penelitian Al-Fellani dkk. (2007) dan sebagian besar gejala klinis yang muncul akibat infeksi Blastocystis sp. adalah diare.

\section{Metode penelitian \\ Pemeriksaan Sampel}

Pengambilan sampel feses diambil secukupnya lalu dimasukkan ke dalam pot sampel dan ditambahkan kalium dikromat $2 \%$ 
sebagai bahan pengawet. Setiap pot sampel diberi label menggunakan spidol atau kertas label.

Setelah dilakukan pengambilan sampel feses di Kecamatan Labang Kabupaten Bangkalan, selanjutnya dilakukan pemeriksaan sampel feses menggunakan metode sederhana (natif), sedimentasi, dan apung di Laboratorium Parasitologi Veteriner Fakultas Kedokteran Hewan, Universitas Airlangga Surabaya.

\section{Metode Sederhana}

Feses diambil dengan menggunakan ujung gelas pengaduk yang kecil yang dioles pada kaca obyek, kemudian diberi satu-dua tetes air, diratakan, dan ditutup menggunakan kaca penutup. Kemudian diperiksa di mikroskop dengan perbesaran $100 \mathrm{x}$. Eosin diberikan untuk membuat kontras antara telur cacing dan sekitarnya (Mumpuni dkk., 2017).

\section{Metode Sedimentasi}

Suspensi feses dibuat dengan perbandingan feses dan air 1:10. Suspensi diaduk dan disaring menggunakan saringan yang ditampung ke dalam gelas plastik. Hasil saringan atau filtrat dimasukkan ke dalam tabung sentrifus dan disentrifus dengan kecepatan $1500 \quad \mathrm{rpm}$ selama 2-5 menit. Supernatan dibuang, kemudian endapan ditambah air dan disentrifus kembali. Proses ini dilakukan berulang-ulang hingga menghasilkan supernatan yang jernih. Setelah proses sentrifus terakhir, supernatan jernih dibuang dan disisakan sedikit, endapan diaduk kemudian ambil sedikit endapan menggunakan pipet Pasteur, endapan diletakkan pada kaca obyek dan ditutup menggunakan kaca penutup kemudian diperiksa dengan mikroskop perbesaran 100x (Mumpuni dkk., 2017).

\section{Metode Pengapungan Fulleborn}

Suspensi feses dibuat dengan perbandingan feses dan air 1:10. Suspensi diaduk dan disaring menggunakan saringan yang ditampung ke dalam gelas plastik. Hasil saringan atau filtrat dimasukkan ke dalam tabung sentrifus dan disentrifus dengan kecepatan $1500 \mathrm{rpm}$ selama 2-5 menit. Supernatan dibuang, kemudian endapan ditambah air dan disentrifus kembali. Proses ini dilakukan berulang-ulang hingga menghasilkan supernatan yang jernih. Setelah proses sentrifus terakhir, supernatan jernih dibuang dan diganti dengan larutan gula jenuh sampai $1 \mathrm{~cm}$ dari mulut tabung lalu disentrifus kembali dengan cara yang sama. Tabung sentrifus diletakkan pada rak tabung dan ditambahkan larutan gula jenuh hingga terlihat cembung pada mulut tabung sentrifus. Kemudian, kaca penutup diletakkan di atas tabung sentrifus dan dibiarkan selama 1-2 menit. Setelah itu kaca penutup diambil dan diletakkan di atas kaca obyek, dan diperiksa di bawah mikroskop (Mumpuni dkk., 2017).

\section{Identifikasi Protozoa}

Sampel feses kambing yang dikoleksi dari Kecamatan Labang Kabupaten Bangkalan dinyatakan sampel positif apabila telah dilakukan pemeriksaan feses dan ditemukan protozoa dengan melihat morfologi serta pengukuran pada protozoa menggunakan kunci identifikasi Soulsby (1986).

\section{Pengumpulan Data}

Sampel yang postif dihitung angka prevalensinya dengan rumus Prevalensi dihitung berdasarkan sampel $+/$ total sampel dinyatakan dalam \%. Hasil prevalensi menunjukan tingkat suatu masalah pada penyakit untuk tujuan administratif dan dapat digunakan sebagai pertimbangan strategi dalam pengendalian penyakit (Thrusfield, 2005).

\section{Analisis Data}

Data dari penelitian ini dianalisis menggunakan metode Chi Square Test menggunakan program Statistical Product and Service Solution (SPSS) 25 for windows untuk mengetahui pengaruh umur dan jenis kelamin kambing terhadap prevalensi infeksi protozoa saluran pencernaan pada kambing.

\section{Hasil dan Pembahasan}

Hasil penelitian mengenai perhitungan angka prevalensi dan identifikasi protozoa saluran pencernaan yang dilaksanakan pada bulan April - Juli 2019 berdasarkan pemeriksaan laboratorium dengan metode natif, sedimentasi, dan pengapungan pada 100 sampel feses kambing di Kecamatan Labang Kabupaten Bangkalan diperoleh 84 sampel positif dan 16 sampel negatif. Protozoa yang ditemukan pada sampel feses kambing di Kecamatan Labang Kabupaten Bangkalan terdiri dari 2 genus, yaitu Eimeria sp. sebesar 8o\% sampel positif, dan Blastocystis sp. sebesar $23 \%$ sampel positif, selengkapnya disajikan dalam Tabel 1. 
Infeksi satu spesies pada sampel feses kambing sebanyak 65 sampel positif yang terdiri dari infeksi Eimeria sp. sebanyak 61 sampel positif dan Blastocystis sp. sebanyak 4 sampel positif. Infeksi dua spesies yaitu ditemukan Eimeria sp. dan Blastocystis sp. sebanyak 19 sampel positif. Jenis protozoa yang ditemukan berdasarkan jenis kelamin, kelompok umur, dan jenis kejadian infeksi selengkapnya disajikan pada Tabel 2.

Hasil penelitian menunjukkan bahwa angka prevalensi infeksi protozoa saluran pencernaan pada kambing di Kecamatan Labang, Kabupaten Bangkalan sebesar 84\% dari
100 sampel yang telah diperiksa. Data yang diperoleh yaitu prevalensi protozoa saluran pencernaan pada kambing umur kurang dari 1 tahun sebesar 9o\% dengan jumlah sampel positif sebanyak 18 sampel dari 20 sampel. Prevalensi protozoa saluran pencernaan pada kambing dengan umur lebih dari 1 tahun sebesar 82,5\% dengan jumlah sampel positif sebanyak 66 sampel dari total 80 sampel. Hasil analisis Chi Square diperoleh nilai yang tidak signifikan yaitu sebesar 0,332 yang menunjukkan tidak adanya perbedaan yang nyata dengan nilai $(\mathrm{p}>$ o,05).

Tabel 1. Prevalensi Infeksi Protozoa Saluran Pencernaan pada Kambing di Kecamatan Labang Kabupaten Bangkalan

\begin{tabular}{ccccccc}
\hline \multirow{2}{*}{ Sampel } & \multicolumn{3}{c}{ Infeksi } & \multicolumn{3}{c}{ Jenis Protozoa } \\
\cline { 2 - 7 } & Jenis Infeksi & Jumlah & Presentase (\%) & Protozoa & Jumlah & Presentase (\%) \\
\hline \multirow{2}{*}{ Positif } & \multirow{2}{*}{ Tunggal } & $65 / 84$ & 65 & Eimeria sp. & $61 / 84$ & 61 \\
& & & & Blastocystis sp. & $4 / 84$ & 4 \\
& Campuran & $19 / 84$ & 19 & Eimeria sp. dan & $19 / 84$ & 19 \\
Negatif & - & 16 & 16 & Blastocystis sp. & 16 & 16 \\
\hline Total & & 100 & 100 & & 100 & 100
\end{tabular}

Tabel 2. Jenis protozoa berdasarkan jenis kelamin, kelompok umur, dan jenis kejadian infeksi yang menginfeksi kambing di Kecamatan Labang, Kabupaten Bangkalan

\begin{tabular}{|c|c|c|c|c|c|c|}
\hline \multirow{2}{*}{ Jantan } & \multirow{2}{*}{$\begin{array}{l}\text { Jumlah } \\
\text { sampel }\end{array}$} & \multirow{2}{*}{$\begin{array}{c}\text { Total Sampel } \\
\text { Positif }\end{array}$} & \multicolumn{4}{|c|}{ Sampel positif terinfeksi protozoa } \\
\hline & & & Tunggal & Jumlah & Campuran & Jumlah \\
\hline$<1$ Tahun & 8 & 7 & Eimeria sp. & 6 & $\begin{array}{l}\text { Eimeria sp. } \\
\text { dan } \\
\text { Blastocystis } \\
\text { sp. }\end{array}$ & 1 \\
\hline$>1$ Tahun & 18 & 16 & $\begin{array}{l}\text { Eimeria sp. } \\
\text { Blastocystis sp. }\end{array}$ & $\begin{array}{l}13 \\
1\end{array}$ & $\begin{array}{l}\text { Eimeria sp. } \\
\text { dan } \\
\text { Blastocystis } \\
\text { sp. }\end{array}$ & 2 \\
\hline Total jantan & 26 & 23 & & 20 & & 3 \\
\hline \multicolumn{7}{|l|}{ Betina } \\
\hline$<1$ Tahun & 12 & 11 & Eimeria sp. & 10 & $\begin{array}{l}\text { Eimeria sp. } \\
\text { dan } \\
\text { Blastocystis } \\
\text { sp. }\end{array}$ & 1 \\
\hline$>1$ Tahun & 62 & 50 & $\begin{array}{l}\text { Eimeria sp. } \\
\text { Blastocystis sp. }\end{array}$ & $\begin{array}{l}32 \\
3\end{array}$ & $\begin{array}{l}\text { Eimeria sp. } \\
\text { dan } \\
\text { Blastocystis } \\
\text { sp. }\end{array}$ & 15 \\
\hline Total betina & 74 & 61 & & 45 & & 16 \\
\hline Total & 100 & 84 & . & 65 &. & 19 \\
\hline
\end{tabular}


Pengaruh jenis kelamin terhadap angka prevalensi protozoa saluran pencernaan pada kambing juga diperoleh nilai yang tidak signifikan. Sebesar 61 sampel positif dari 74 sampel yang diperiksa dengan persentase sebesar 82,4\% pada kambing betina. Angka prevalensi protozoa pada kambing jantan yaitu 23 sampel positif dari total 26 sampel dengan persentase sebesar $88,5 \%$. Hasil analisis Chi Square juga diperoleh nilai yang tidak signifikan yaitu sebesar 0,353 . Hal ini menunjukkan tidak adanya perbedaan yang nyata dengan nilai $(\mathrm{p}>$ $0,05)$.

Spesies protozoa yang ditemukan dari hasil pemeriksaan sampel feses kambing menggunakan metode pengapungan Fulleborn dapat dilihat pada Gambar 1.
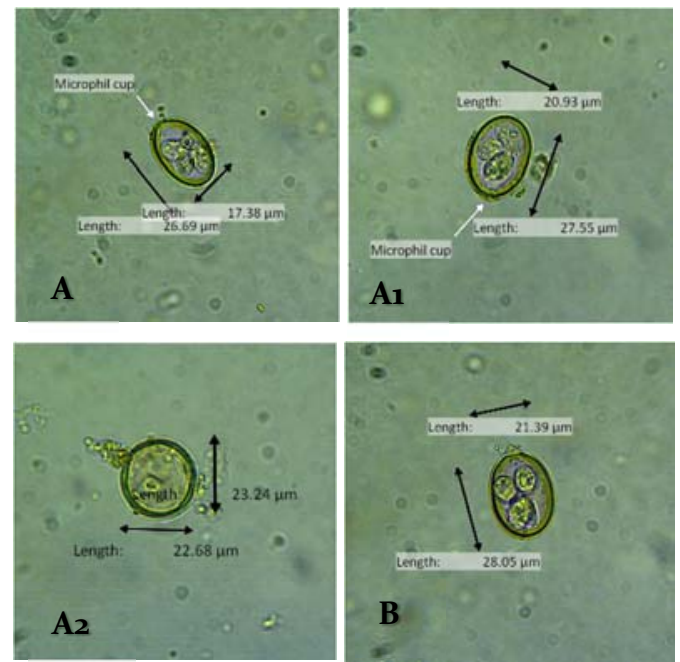

Gambar 1. Gambar protozoa yang ditemukan. Eimeria arloingi (A); Eimeria christenseni $\left(\mathrm{A}_{1}\right)$; Eimeria caprovina (A2) ; dan Blastocystis sp. (B). Perbesaran 40ox.

Ciri umum Eimeria sp. yang telah bersporulasi yaitu memiliki 4 sporokista yang nampak jelas, memiliki dinding dua lapis, lapis terluar tidak berwarna sedangkan lapisan dalam berwarna gelap. Berdasarkan bentuk dan ukuran yang berbeda, terdapat tiga spesies Eimeria sp. yang menginfeksi kambing di Kecamatan Labang Kabupaten Bangkalan yang diduga sebagai spesies Eimeria arloingi, Eimeria christenseni, dan Eimeria caprovina. Eimeria arloingi (A) memiliki bentuk ellipsoid, terdapat microphil cup, dan berukuran $26,69 \mu \mathrm{m} \times 17,38$ $\mu \mathrm{m}$; Eimeria christenseni $\left(\mathrm{Al}_{1}\right)$ berbentuk ovoid, terdapat microphil cup, dan berukuran $27,55 \mu \mathrm{m}$ x 20,93 $\mu \mathrm{m}$; dan Eimeria caprovina (A2) yang memiliki bentuk ovoid tetapi tidak terdapat microphil cup serta berukuran 28,05 $\mu \mathrm{m}$ x 21,39 $\mu \mathrm{m}$. Sampel feses kambing yang diperiksa dengan metode pengapungan juga dapat ditemukan protozoa Blastocystis sp. yang memiliki bentuk bulat vakuolar dengan ukuran 23,24 x 22,68 $\mu \mathrm{m}$.

Pada beberapa penelitian sebelumnya, angka infeksi Eimeria pada kambing di setiap negara berbeda-beda. Prevalensi Eimeria sebesar $89 \%$ di Negara Malaysia dan $71 \%$ dari sampel positif ditemukan Eimeria arloingi (Jalila dkk., 1998). Deger dkk. (2003) di Turki mendeteksi adanya infeksi Eimeria sp. sebesar 73,6\% dari total 242 sampel, Rehman dkk. (2011) di Pakistan mendeteksi Eimeria sp. sebesar 55,99\% dari 121 sampel, dan Cavalcante dkk. (2012) di Brazil, mendeteksi infeksi Eimeria sp. sebesar 91,2\% dari 215 sampel. Infeksi Eimeria sp. lebih banyak terjadi pada musim hujan dan terjadi peningkatan infeksi karena kelembaban lingkungan menguntungkan protozoa untuk bersporulasi (Kumar dkk., 2016). E. christenseni, E. arloingi, E. caprina, dan E. ninakohlyakimovae dilaporkan sebagai spesies yang sangat patogenik (Khodakaram-Tafti dan Hashemnia, 2017).

Genus protozoa lain yang ditemukan yaitu Blastocystis sp. yang memiliki bentuk bulat vakuolar dan berukuran 23,24 x 22,68 $\mu \mathrm{m}$. Penelitian ini melaporkan adanya infeksi Blastocystis sp. sebesar 23\%. Spesies ini bersifat zoonosis dan memiliki resiko penularan yang besar pada manusia jika terjadi kontak dengan hewan yang positif terinfeksi Blastocystis. Prevalensi Blastocystis sp. di China sebesar 0,3\% dan di Malaysia sebesar 30,9\%. Perbedaan angka prevalensi dan infeksi dikaitkan dengan banyak faktor antara lain metode pemeriksaan, usia, ukuran sampel, musim, dan beberapa lainnya (Tan dkk., 2013 dan Li dkk., 2018).

Angka prevalensi yang didapat berkaitan dengan beberapa hal yaitu kondisi lingkungan, iklim, serta manajemen pakan dan kandang. Konstruksi kandang kambing yang ada di Kecamatan Labang Kabupaten Bangkalan mayoritas menggunakan kandang panggung yang terbuat dari bambu. Menurut Rupa dan Portugaliza (2016), kambing yang dipelihara dengan model kandang beralaskan bambu memiliki prevalensi sebesar 98,61\% dibandingkan dengan kambing yang konstruksi kandangnya terbuat dari semen $(91,91 \%)$. Hal ini disebabkan karena kandang yang terbuat dari bambu lebih sulit dibersihkan sehingga sanitasi kandang kurang terjaga. Angka prevalensi protozoa di negara berkembang (30-50\%) lebih 
tinggi dibandingkan negara maju $(1,5-10 \%)$. Tinggi angka prevalensi di negara berkembang dipengaruhi oleh beberapa hal antara lain populasi yang padat, kondisi lingkungan yang buruk, dan sistem pembuangan limbah yang tidak tepat (Badparva dkk., 2015).

\section{Kesimpulan}

Berdasarkan hasil pemeriksaan 100 sampel feses kambing di Kecamatan Labang Kabupaten Bangkalan, angka prevalensi infeksi protozoa saluran pencernaan pada kambing di Kecamatan Labang Kabupaten Bangkalan sebesar $84 \%$. Genus protozoa saluran pencernaan yang menginfeksi kambing di Kecamatan Labang Kabupaten Bangkalan yaitu Eimeria sp. dan Blastocystis sp. Umur dan jenis kelamin memiliki pengaruh yang sama terhadap infeksi protozoa saluran pencernaan pada kambing di Kecamatan Labang Kabupaten Bangkalan.

\section{Daftar Pustaka}

Alexander, J. and W. H. Stimson. 1988. Sex Hormones and The Course of Parasitic Infection. Parasitology Today. 4:189-93.

Al-Fellani, M. A., A. H. Khan, R. M. Al-Gazoui, M. K. Zaid, and M. A. Al-Ferjani. 2007. Prevalence and Clinical Features of Blastocystis hominis Infection among Patients in Sebha, Libya. Sultan Qaboos University Mededical Journal. 7(1): 35-40.

Badparva, E., S. Fallahi, Z. Arab-Mazar. 2015. Blastocytis: Emerging Protozoan Parasite with High Prevalence in Iran. Iran. Novelty in Biomedicine. 4:214-221.

Cavalcante, A. C. R., M. Teixeira, J. P. Monteiro, and C. W. G. Lopes. 2012. Eimeria species in dairy goats in Brazil. Veterinary Parasitology. 183:356-358. doi: 10.1016/ j.vetpar.2011.07.043.

Daugschies, A. And M. Najdrowski. 2005. Eimeriosis in cattle: current understanding. Journal of Veterinary Medicine B Infectious Diseases and Veterinary Public Health. $52(10): 417-27$.

Deger, S., A. Gul, E. Ayaz, and K. Blcek. 2003. The prevalence of Eimeria species in goats in Van. Turkish Journal of Veterinary and Animal Sciences. 27:439-442.

Dinas Peternakan Provinsi Jawa Timur 2018. Data Statistik Populasi Ternak Kab/Kota di
Jawa Timur. //http: disnak.jatimprov. go.id/web/layananpublik.

Jalila, A., P. Dorny, R. Sani, N. B. Salim, and J. Vercruysse. 1998. Coccidial infections of goats in Selangor, peninsular Malaysia. Veterinary Parasitology. 74:165-172.

Jittapalapong, S., S. Saengow, N. Pinyopanuwat, W. Chimnoi, W. Khachaeram, and R. W. Stich. 2012. Gastrointestinal Helminthic and Protozoal Infections of Goats in Satun, Thailand. Journal of Tropical Medicine and Parasitology. 35:48-54.

Khodakaram-Tafti, A. and M. Hashemnia. 2017. An overview of intestinal coccidiosis in sheep and goats. Revue Médecine Vétérinaire. 168, 1-3, 9-20.

Kumar, B., B. R. Maharana, A. Prasad, J. P. Joseph, B. Patel, and J. S. Patel. 2016. Seasonal incidence of parasitic diseases in bovines of south western Gujarat (Junagadh), India. Journal Parasit Disease. 40(4):1342-1346.

Levine, N. D. 1995. Protozoologi Veteriner (terjemahan). Alih Bahasa: Soekardono, S. Gadjah Mada University Press. Yogyakarta. 124-478.

Li, W. C., K. Wang, and Y. Gu. 2018. Occurrence of Blastocystis sp. and Pentatrichomonas hominis in sheep and goats in China. Parasit Vectors.11(1):93. Published 2018 Feb 17. doi:10.1186/s13071-018-2671-5.

Mumpuni, S., S. Subekti, S. Koesdarto dan Kusnoto. 2017. Penuntun Praktikum Ilmu Penyakit Helminth Veteriner. Fakultas Kedokteran Hewan Universitas Airlangga. Surabaya. 7-10.

Rehman, T. U., M. N. Khan, I. A. Khan, and M. Ahmad. 2011. Epidemiology and economic benefits of treating goat coccidiosis. Pakistan Veterinary Journal. 31(3):227-230.

Rupa, A. P. M., and H. P. Portugaliza. 2016. Prevalence and Risk Factors Associated with Gastrointestinal Nematode Infection in Goats Raised in Baybay city, Leyte, Philippines. Veterinary World. 9(7):728734 .

Soulsby, E. J. L. 1986. Helmint, Arthropoda, and Protozoa of Domesticated Animals. $7^{\text {th }}$ edition Bailliere Tindall. London. 505-757. 
Tan, T. C., P. C. Tan, R. Sharma, S. Sugnaseelan, and K. G. Suresh. 2013. Genetic diversity of caprine Blastocystis from peninsular Malaysia. Parasitology Research. 112:85-89. doi: 10.1007/s00436-012-3107-3.

Thlama, P. B., B. A. Abdullahi, G. M. Ahmed, A. Mohammed, M. H. Philip, and J. Yusuf. 2016. Point Prevalence and Intensity of Gastrointestinal Parasite Ova/Oocyst and Its Association with Body Condition Score (BCS) of Sheep and Goats in Maiduguri, Nigeria. The Journal of Advances in Parasitology. 3: 81-88.
Thrusfield, M. 2005. Veterinary Epidemology $3^{\text {rd }}$ edition. Butterworths. London. 53.

Yulianto, E. 2007. Hubungan Higiene Sanitasi Dengan Kejadian Penyakit Cacingan Pada Siswa Sekolah Dasar Negeri Rowosari or Kecamatan Tembalang Kota Semarang Tahun Ajaran 2006/2007. [Skripsi] Fakultas Kesehatan Masyarakat. Universitas Negeri Semarang.

Zalizar, L. 2017. Helminthiasis Saluran Cerna Pada Sapi Perah. Jurnal Ilmu-Ilmu Pertenakan. 27(2): 116-122. 